\title{
Aplicação do Mapeamento do Fluxo de Valor Através do Sistema Lean: o Caso de Uma Empresa de Tratamento de Chapas Em Aço Carbono
}

Value stream mapping via lean system: case study of a plate treatment carbon steel company.

Thássio José V.B. Gomes orcid.org/0000-0001-5727-2427

Ana de Fátima Braga Barbosa orcid.org/0000-0001-5727-2427

E-mail do autor principal: Thássio José V.B. Gomes thassiobeserra@gmail.com

\section{Resumo}

Tratando-se de produção em massa, o pensamento é produzir cada vez mais. O sistema Lean de produção propõe o uso de ferramentas para ajudar a gerir problemas, visando produzir somente o necessário, no tempo certo, com baixo custo. O mapeamento de fluxo de valor é uma ferramenta que auxilia no entendimento do fluxo de material e de informação, na medida em que o produto segue o fluxo de valor. Ela consiste em desenhar cada processo de produção de um produto desde o fornecedor até o consumidor. Através do mapeamento do fluxo de valor é que os pontos críticos poderão ser evidenciados para tratamento, melhorando o processo produtivo. A pesquisa descritiva e exploratória, aplicada a uma empresa de tratamento de chapas, situada no Complexo Portuário de Suape, dá relevância ao processo de produção em massa, sendo uma das metodologias do Lean.

Palavras-Chave: Sistema de produção; Produção enxuta; Mapeamento de fluxo de valor.

\section{Abstract}

Regarding mass production, main intention is produce more and more. Lean production system proposes the use of tools to help manage problems in order to produce only what is necessary, at the right time, with low cost. Value flow mapping is a tool that helps to understand the flow of material and information as the product follows the value flow. It consists in designing each production process of a product from the supplier to the consumer. Through the value mapping flow, critical points can be foundfor analysis and treatment, improving more and more the productive process. The descriptive and exploratory research, carried out at a plate metal processing company located in the Suape Port Complex, shows how relevant it is to a mass production process, with one of the Lean methodology.

Key-words: Production System; Lean production; value stream mapping 


\section{Introdução}

É preciso, cada vez mais, aperfeiçoar os métodos de trabalho fazendo com que seja mais bemutilizado o tempo produtivo, levando em conta vários fatores, dentre eles, a preocupação emproduzir somente o que for necessário, atender às necessidades do cliente em menor tempo, com boa qualidade e não havendo desperdícios, sejam eles quais forem.

O sistema Leanou produção enxuta é oriundo do Japão; criado pela Toyota Motors. No início era usado em indústria automobilística, mas, com o passar dos anos foi implantado em todos os segmentos, alcançando bons resultados, segundo o qual, em todo processo produtivo, existem pontos que devem ser melhorados, buscando sempre boa produção, lucros, bem-estar dos colaboradores, e estas ferramentas podem facilitar essa busca.

Womack [1], afirma que esse tipo de manufatura, implementada pela Toyota, deixa diversos outros segmentos curiosos, a fim de entenderem como funciona, além do que, a produção Lean é um assunto abordado mundialmente, atrelado ao sucesso da qualidade total, iniciado na década de 80 .

Segundo Liker [2], para implementar esse programa de trabalho é fácil, sendo a maior dificuldade a mudança de cultura; no Japão evoluiu de maneira natural, mas passando por altos e baixos.

EnsinaLiker [2] que a metodologiaLean é aplicável a qualquer ambiente, que traz duas visões: uma tradicional e uma visão da Toyota. A primeira, com o objetivo de copiar de outras empresas esse método, já na visão Toyota, ondevaria em cada empresa, devendo ela identificar e solucionar os seus problemas.

Mas de acordo com a ideia de Werkena [3], o mapeamento de Fluxo de Valor (MFV), uma das ferramentas da produção enxuta (Lean),é utilizado para mapear todas as atividades que agregam valor à produção, demonstrando o passo a passo delas. A produção enxuta, como é conhecida o Lean, almeja diminuir desperdícios em meio aos processos produtivos, ajustando a fábrica para que os outputs sejam entregues em tempo hábil e com menor custo.

A produção enxuta remeteàmelhoria no processo produtivo, onde é de suma importância a utilização de suas ferramentas, cuja filosofia pode ser aplicada em qualquer ramo de atividade, trazendo ganhos notórios à organização.

Partindo das teorias já mencionadas, éapresentado como utilizar ferramentas do sistema Lean, para identificar oportunidades de melhorias na empresa de tratamento de chapas.

Ametodologia aplicada nesse estudo classifica-se em descritiva eos métodos, em pesquisa bibliográfica e estudo de caso. Esse método de gestão é de suma relevância para qualquer corporação, pois nela os dados são reais, fazendo com que as tomadas de decisões sejam precisas e eficientes, facilitando o objetivo final: lucro.

\section{Objetivos}

\subsection{Geral}

Analisar, aplicar e executar o mapeamento do fluxo, de uma linha de produção de pintura de chapas, a fim de realizar melhorias no processo produtivo.

\subsection{Específicos}

- Descrever o processo de produção da fábrica;

- Aplicar o Mapeamento do Fluxo de Valor;

- Obter dados para estudo;

- Apresentar melhorias na linha produtiva;

\section{Referencial Teórico}

\subsection{Conceitos de Sistema de Produção}

Segundo Marques [4], define-se sistemas como vários elementos que dependem um do outro com foco em um só propósito, onde os sistemas de produção são diversas atividades que estão ligadas umas às outras, com o único objetivo, produzir bens ou serviços, que é o processo de transformação de inputs(entradas) em outputs (saídas).

Cada organização trabalha de um modo diferente da outra, para adotar um sistema de produção de 
forma a realizar sua produção da melhor forma possível [5].

De acordo com Jacobs [6], é através do sistema de produção que a empresa gerencia de maneira organizada suas matérias primas, seus insumos, passando pelo processo detransformação até chegar ao estoque final, produto acabado.

Diante disso,Moreira [5] relata que um sistema de produção é a conjunção de diversos elementos como: máquinas, mão de obra, ferramentas nas quais são planejados com foco principal na transformação de insumos em produtos.Sistema de produção é o conjunto de partes que se relacionam entre si atuando nas entradas, priorizando produzir saídas. [7]

É o sistema de produção que corresponde ser a parte ativa da organização, no qual está ligada em torná-la sempre competitiva e obter sucesso na venda de bens e serviços. [7]

Sistemas de produção são operações e atividades ligadas entre si que se envolvem na produção de bens ou serviços. É a parte do sistema da organização e permite a interação com fornecedores, ambiente, energia e mão de obra.

Caxito [8] define sistema de produção como grupossemiautônomosfocadospor montagens de produtos posicionados ergonomicamente bem, com ciclo de posições que duram horas.

Para eliminar os desperdícios, têm que analisar toda a fábrica, no contexto das atividades realizadas, visando apontar quais agregam valores à produção. [9]

Através desse pensamento, Corrêa [11] remete que para esclarecer essas atividades ele utiliza as características propostas por ShigeoShingo, engenheiro da Toyota Motor Company, do Japão. São essas categorias de desperdícios descritas abaixo:

\section{Categorias de desperdícios:}

- Superprodução: O Just In Time - JIT considera desperdício fabricar antecipadamente para se ter no futuro. Assim, esta filosofia sugere a produção de somente o que se faz necessário para aquele momento.

- Transportes: A atividade de manuseio das cargas ou transportes delas, não agrega valor ao produto produzido. Isso se dá pelo arranjo físico do setor, fazendo com que haja um deslocamento desnecessário. Esse deve ser eliminado com um layoutadequado, minimizando as distâncias a serem percorridas.

- Processamento: No próprio processo produtivo tem desperdícios que, para favorecer a rapidez, aparecem sem serem notados. Assim, se faz importante a aplicação de métodos de engenharia e análise de valor, reduzindo componentes necessários para fabricação de determinados produtos.

- Movimentação: Esse tipo de desperdício estápresente nas mais variadas operações dentro de uma fábrica. A produção enxuta visa economizar esses movimentos, pois gera mais produtividade e qualidade.

- Refugos: Um dos maiores desperdícios são os problemas com qualidade. Produção de produtos defeituosos significa gastos com materiais, mão de obra, equipamentos, estocagem entre outros.

- Inventário: Produtos/materiais que não estão no fluxo produtivo.

- Estoque:Como todos os outros, esse também gera muito retrabalho, desperdício de espaço e investimento. Através da eliminação das causas geradoras é que se combate essa perda. [11]

Assim, deve ser produzido somente o necessário e em quantidades exatas, evitando gastos desnecessários, e promovendo amaximização dos lucros e ótimos resultados, utilizando ferramentas do sistema Leande produção. Evitar esses desperdícios,é possível economizar, pois realizando a superprodução, seránecessário mais transporte, aumentando o número da frota e de funcionários, e ainda, com a possibilidade de fabricar produtos defeituosos, com má qualidade, oquegerarretrabalho, requer que haja mais esforços desnecessários para a sua fabricação.

\section{As cincos principais ferramentas da produção enxuta}

Para usar os princípios Lean, se faz necessário o utilizar algumas ferramentas com devido comprometimento. Slack [9] retrata algumas delas:

*5s:Uma das mais usadas com um simples pensamento de arrumação de casa para facilitar a http://dx.doi.org/10.25286/repa.v4i1.849 
ordem visual, melhorar o ambiente de trabalho, maximizar os recursos, aperfeiçoar o layout, entre outros.

A terminologia " 5 s" veio do Japão, época em que procurava se reestruturar após a guerra em seu país. "5S" vem de cinco letras japonesas que são: SEIRI, SEITON, SEISO, SEIKETSU e SHITSUKE e que significam: inútil.

$1^{\circ}$ S- SEIRI(Senso de utilização) - Separar o útil do

$2^{\circ} \mathrm{S}$-SEITON(Senso de arrumação) - Identificar as coisas e arrumá-las de tal forma que sejam alcançados por qualquer um quando necessário.

$3^{\circ} \mathrm{S}$-SEISO(Senso de limpeza) - Manter um ambiente sempre limpo, nenhuma sujeira na área de trabalho.

$4^{\circ}$ S-SEIKETSU(Senso de Saúde e Higiene) Manter um ambiente de trabalho límpido e favorável à saúde e higiene.

$5^{\circ} \mathrm{S}$-SHITSUKE (Senso de Disciplina) - Desenvolver um hábito do 5 se transformá-lo em modo de vida.

*Kanban:essa palavra origina-se do japonês que significa "cartão" ou "registro visível", usado para controlar o fluxo de produção da fábrica.

Esse método define como produzir, movimentar os produtos, e entregá-los de forma controlada. O material fabricado é limitado pelo número de cartões em circulação, facilitando a visão geral e eliminando a burocracia.

*Kaizen:que significa melhoria contínua, mas para outros significa (Kai= mudar, Zen=bem), ou seja, mudança para o bem. Essa ferramenta tem o objetivo de reduzir os desperdícios, procurar melhorar todo o processo, seja na parte de qualidade ou na parte produtiva.

Ficou conhecida no mundo por ser aplicada no Sistema Toyota de Produção (TPS), onde qualquer colaborador pode dar uma ideia de melhoria, e ela ser aplicada com o intuito de ajudar o processo produtivo.

*Mapeamento de Fluxo de Valor (MFV): segundo Slack [9] é uma metodologia representada visualmente para entender todo o fluxo de material, desde a entrada (Input) até sua saída (Output), mapeando todo o caminho da produção, seja de um produto ou serviço.

Slack [9] ensina que consiste em mapear o estado atual, um estado futuro e um plano de implementação desse estado futuro. No estado atual são identificados diversos problemas que interferem no processo produtivo, que devem constar no plano de implementação para inclusão no estado futuro.
*Six sigma: seis sigma objetiva uma mudança radical na parte do desempenho da empresa e sua lucratividade, com o foco na melhoria da qualidade dos processos e produtos, fazendo com que aumente o controle de qualidade.

Elas reforçam a importância no processo produtivo de qualquer organização, facilitando a gestão, eliminando o que não agrega valor a determinada atividade ou serviço. Depois de mapeado o estado atual é que a empresa planejará, realizando metas e mudanças para o estado futuro. $\mathrm{E}$, em meios a esses planos, poderão utilizar de outras ferramentas como o 5s eKanban, apoiando para o objetivo final ser mais eficiente.

\section{Mapeamento do fluxo de valor (MFV)}

Para Rotear e Shok [12], um fluxo de valor é uma ferramenta simples, mas que exige um pouco de cautela ao realizá-la, utilizando apenas lápis e papel. Mapear todo o fluxo de material, desde a entrada da cadeia de valor até a saída, ajuda a enxergar como um todo, eliminando os pontos fracos. Após mapear o estado de valor atual, o próximo passo e definir o estado futuro.

Ela serve para demonstrar como está o estado atual do processo produtivo hoje, fazendo assim, uma análise comparativa de como ela está e como deveria estar. Depois de mapeada, os gestores tomarão decisões quanto à sua produção diária, mensal e até mesmo anual, para definir se irão aumentar a produção, se irão diminuir, ou seja, só depois de utilizá-la é que poderão se programar melhor[10].

Segundo Slack [9], após o mapeamento será observado o desperdício e, com isso, se faz uma análise para identificar suas causas. São quatro passos para a identificação desses desperdícios:

*Primeiro: saber qual área serámapeada;

*Segundo: mapear toda a área escolhida, identificando quais pontos agregam valor às atividades analisadas;

*Terceiro: são enfatizados os problemas com suas respectivas melhorias, almejando o Mapeamento de Fluxo de Valor (MFV) futuro;

*Quarto: implementação das melhorias detectadas no terceiro passo.

Esta pode ser analisada por todos os envolvidos, trazendo diversos efeitos para melhorar toda a produção, mostrando como está o processo hoje e gerenciando o mesmo para cada vez mais conseguir competitividade. Slack [9]. 
Pizza e Amestrei [13], afirmam que o Mapeamento de Fluxo de Valor (MFV), ajudará a identificar os desperdícios e também suas causas. Depois de mapeado o estado atual, ficará mais fácil de gerenciar o processo buscando mais melhorias.

Essa metodologia traz diversos pontos importantes, de alta relevância para a organização, abordados seguir.

a) Ajuda a visualizar o processo como um todo, não especificamente em atividades individuais;

b) Além de ajudar a identificar os desperdícios, mostra de onde vêm os erros;

c) Sua linguagem é bastante comum ao processo;

d) Conceitos e técnicas enxutas são aplicados ao processo, não deixando infiltrar alternativas;

e) Ele permite dar forma de como será implementado o processo futuro;

f) Única ferramenta que mostra com detalhes o fluxo de informações e materiais;

g) É uma ferramenta qualitativa, que permite como seu processo fabril deve operar.

A partir desses importantes pontos é possível obter ganhos e eliminar alguns aspectos que não agregam valores às atividades. É aplicando o mapeamento atual que se terá umavisãomacro de todo o fluxo, ou até mesmo determinado setores, além do mais, retratará um novo estado, ou seja, de como aquele determinado processo deverá operar no futuro.

\section{Metodologia}

\subsection{Procedimentos Metodológicos}

Segundo Gil [14], a pesquisa descritiva tem como objetivo descrever as características de determinada população e podem ter a finalidade de identificar possíveis relações entre variáveis.

Quanto aos métodos caracterizam-se em uma pesquisa bibliográfica e de estudo de caso. Pesquisa bibliográfica, pois através de livros, redes eletrônicas foi possível referenciar os temas de sistema Lean de produção e Mapeamento de Fluxo de Valor.

De acordo com Gil [14], a pesquisa bibliográfica é descrita através de livros publicados, revistas, jornais, teses e etc.

É também estudo de caso, pois seu foco está direcionado a aplicação de ferramentas a um setor de jateamento e pintura de uma fábrica em Pernambuco, aplicando a esse setor um questionário, descrito no apêndice, além de entrevistas para levantamento de dados.

\subsection{Objetos de Estudo}

A seguir, a pesquisa empírica, aplicando um questionário fechado, com o representante do setor de produção de uma empresa naval, situada no complexo portuário de Suape, emIPOJUCA-PE.

A figura 1 ilustra o ambiente da empresa onde se desenvolveu o presente trabalho.

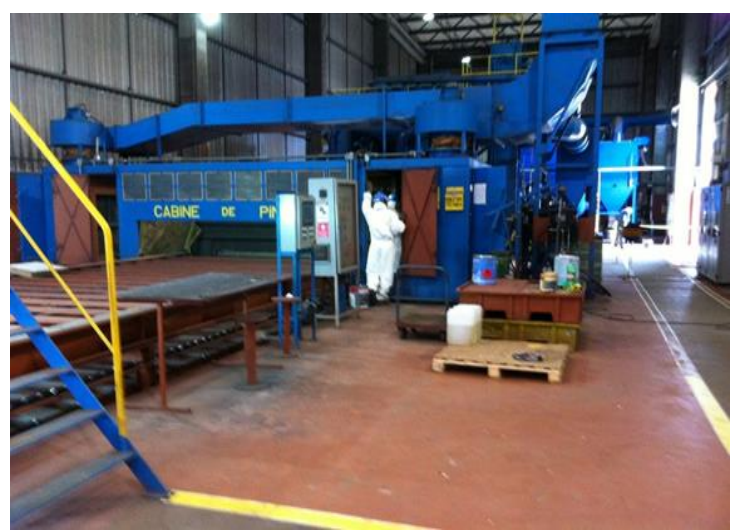

Figura 1- Fábrica de tratamento de chapas. Fonte: autor.

A pesquisa feita in loco, com11colaboradores, é de natureza qualitativa, pois nela se avaliou os níveis de satisfação dos colaboradores, com a implantação de uma nova ferramenta de trabalho, no caso o Mapeamento de Fluxo de Valor.

$\mathrm{Na}$ figura 2 estárepresentado o fluxo atual, demonstrando um total de 11 colaboradores para uma produção diária de 40 chapas, onde foram encontradas 10 melhorias a serem realizadas. Em seguida foi desenhado o mapa do estado futuro.

http://dx.doi.org/10.25286/repa.v4i1.849 


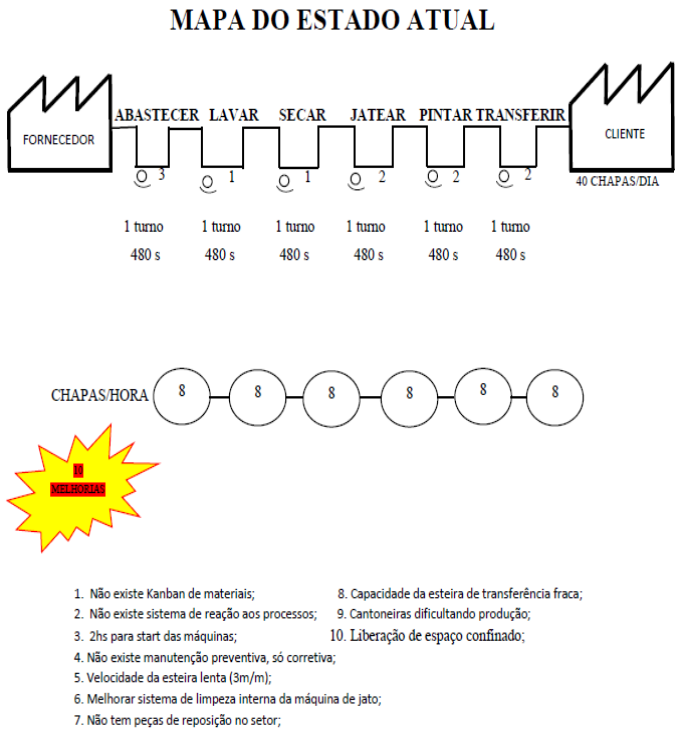

Figura 2-Mapeamento do Fluxo de Valor Atual. Fonte: autor.

A figura 3 mostra a projeção do estado futuro, onde,com apenas 6 colaboradores foi possível sair de uma produção diária de 40 chapas para 60 chapas por dia.

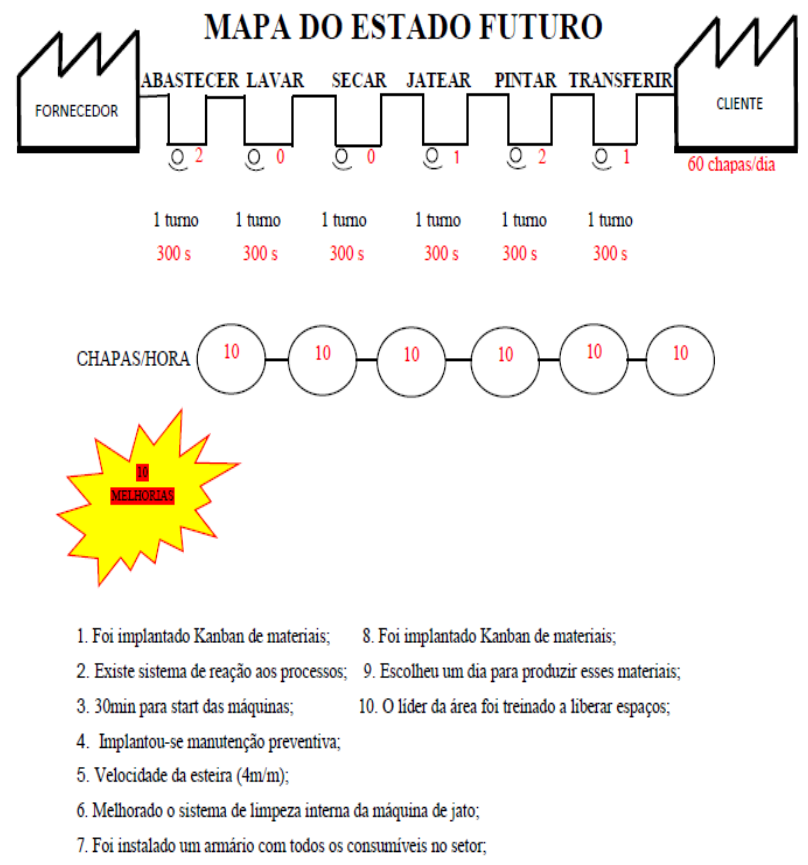

Figura3-Mapeamento do Fluxo de Valor Futuro. Fonte: autor.

\section{Análise dos resultados}

Nessa seção são apresentados os resultados adquiridos pelo questionário fechado realizado com o representante do setor e os colaboradores da área estudada.

De acordo com os apontamentos do gestor da área, é possível obter bons resultados da pesquisa.

O gráfico mostrado na figura 4 permite obter todas as respostas do responsável direto pelo setor e que participou dessa nova ferramenta de trabalho, onde foram feitas 10 perguntas. Tomando por base uma dasperguntas:"depois da aplicação do Mapeamento do Fluxo de Valor foi percebido um ganho na produção?". De acordo com a pesquisa foirespondida a opção como"ótima" visto que, antes era muito desorganizada, a meta oscilava toda semana, dentre outros. E ainda, analisando o gráfico precisamente na questão 10 , onde foi perguntado se ele implantaria essa ferramenta degestão em outra empresa, mais uma vez a resposta foi objetiva, onde o mesmo relatou que tudo muda, seja a maneira produtiva seja o modo de gerir as pessoas, pois esse método também mostra que as pessoas são importantes.

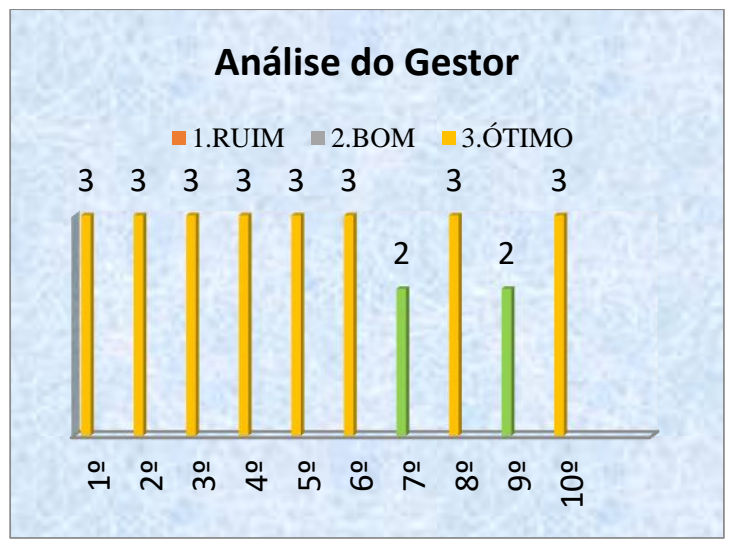

Figura 4-Análise do gestor. Fonte: autor.

As melhorias realizadas após o mapeamento ajudaram em diversos aspectos,comotroca rápida de ferramentas, ergonomia dos colaboradores, arranjo físico dos postos de trabalho, mais tempo para limpezas e manutenção preventiva.

\section{Questionário aplicado aos colaboradores da área.}

A figura 5 aponta o questionario aplicado aos 10 colaboradores, sendo eles operadores, assistentes técnicos, técnico de segurança e líder, a pergunta três, houve $100 \%$ de afirmação que, antes de ser realizado o mapeamento a produção era ruim, em 
relação a alguns pontos como: falta de planejamento, condiçoesprecárias de trabalho, muito retrabalho e que produziam desordenadamente fazendo o máximo de peças possiveis, fazendo com que houvesse um estoque muito alto.

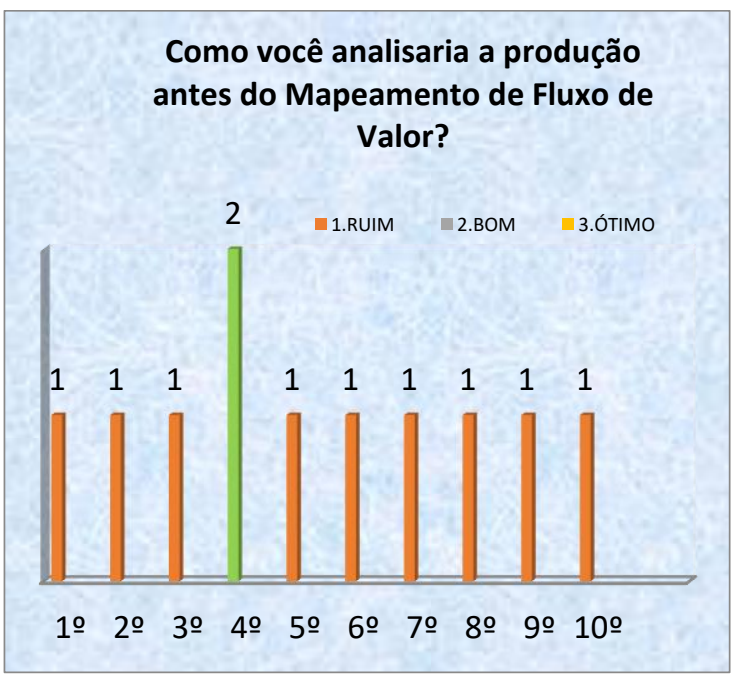

Figura 5-Análise da produção antes do Mapeamento de Fluxo de Valor. Fonte: autor.

Ao realizar o Mapeamento, foramconstatados alguns itens e realizados Kaizen(melhoria contínua), como exemplo o ponto número um, do quadro "estado atual", que relatava que não existia Kanban de materiais, ou seja, quando precisavam de consumíveis, tinham que solicitar ao setor de ferramentaria os itens desejados, onde 0 deslocamento de um setor ao outro era uma distância considerável, e resolvendo essa melhoria, automaticamente,foisolucionadaa questão dois, pois antes o tempo de preparação da máquina de pintura levava em média 2 horas, pois como não tinham materiais para repor, tinham que limpar e instalar antes do início da produção.

Ainda no mapa atual o número não passava de 40 chapas produzidas por dia, pois além dos problemas diversos apresentados nas máquinas a esteira de rolos, que conduziam as chapas não ultrapassava a velocidade de $3 \mathrm{~m} / \mathrm{min}$ (metros por minuto). Hoje, a manutenção preventiva atua em dois turnos e a velocidade da esteira passou para $4 \mathrm{~m} / \mathrm{min}$ (metros por minuto), realizando em média 10 chapas por hora, chegando a produzir 60 chapas/dia.

Vale salientar que antes o quadro efetivo era em 11 colaboradores envolvidos diretamente na atividade. Hoje ficaram6, desempenhando as mesmas atividades e com melhores resultados. A produção em vez de ser "empurrada" tornou-se "puxada", produzindo somente o necessário evitando estoques desnecessários para o cliente final.
Após esse programa de melhoria contínua, o setor, além de melhorar odesempenho produtivo, obteve um ganho com bons níveis de trabalho por parte dos colaboradores, pois os mesmos ingressaram na nova metodologia e estão cada vez maisajudando no que for pertinente a melhoria de sua organização, pois o retorno é notório, e além do mais, o grau de reconhecimento, que antes não tinham, mudou por parte dos gestores, avaliando e implementando as ideias dadas pelos colaboradores, pois são deles que saem as melhores formas de se trabalhar.

\section{Conclusão}

As organizações estão cada vez mais preocupadas em produzir mais com menos custo, buscando ferramentas de gestão cada vez eficazes. O sistema Lean de produção oferece diversas dessas ferramentas que possibilitam menos desperdício, e o Mapeamento de Fluxo de Valor é uma delas.

Essa pesquisa oferece uma nova gestão, pois esse método de trabalho, pode ser usado em qualquer ramo, ajudando a enxergar os problemas, tornando-os visíveis para que sejam eliminados. Desta forma, espera-se que os resultados adquiridos pela pesquisa venham a ampliar os níveis de produtividade tanto por parte dos colaboradores quanto da alta gestão.

Mostrando-se possível validar, que se podem utilizar ferramentas do Leanpara identificar oportunidades de melhoria através do Mapeamento de Fluxo de Valor (MFV).

Diante dos resultados obtidos pode-se concluir que, mapear o processo de produção, ajuda a melhorar o resultado final, e que através desse projeto outras pesquisas possam ser desenvolvidas, mostrando a relevância dessas ferramentas.

\section{Referências}

[1] WOMACK, James P; Jones, Daniel T; ROOS, Daniel. A máquina que Mudou o Mundo,17 edições, Pg. 53, Rio de Janeiro: Campus, 1992.

[2] LIKER, Jeffrey, MICHAEL, Housers. A cultura Toyota: A alma do modelo Toyota, Pg.18, Porto Alegre: Bookman, 2009.

[3] WERKENA, Cristina. Criando a Cultura Lean Seis Sigma, Rio de Janeiro: Elsevier, 2012. 
[4] MARQUES, Cícero Fernandes. Estratégia de Gestão da Produção e Operações, IESDE Brasil, 2012, Pg.21.

[5] MOREIRA, D, A, administração da Produção e Operações, $5^{\circ}$ edição, São Paulo: Pioneira, 2000.

[6] JACOBS, F, Robert, CHASE, B, Richard. Administração da Produção e Operações: $O$ essencial, Pg. 237, São Paulo: Bookman, 2009.

[7] FUSCO, José Paulo Alves, SACOMANO, José Benedito, BARBOSA, Fabio Alves, JUNIOR, Walter Azzolini. Administração de Operações: Da formulação estratégica ao contrato operacional, São Paulo: Arte e Ciência, 2003, Pg25.

[8] CAXITO, Fabiano de Andrade. Produção: Fundamentos e Processos, Curitiba: IESDE, 2008.

[9] SLACK, Nigel; CHAMBERS, Stuart; JOHNSTON, Robert. Administração da Produção, 30 edição, Pg.452, São Paulo, Atlas, 2009.

[10]

KRAJEWSKY, Lee; RITZMAN, Larry; MALHOTRA, Manoj. Administração da Produção, Pg.288,8 edição, São Paulo: Pearson, 2008.

[11] CORRÊA, Henrique L, CORRÊA, Carlos A. Administração da produção e operações:Manufatura e serviços: uma abordagem estratégica, $2^{a}$ Edição, Pg.605, Atlas, 2011.

[12] RHOTER, Mike; SHOOK, John. Aprendendo a Enxergar, mapeando o fluxo de valor para agregar valor e eliminar o desperdício, LeanInstitute Brasil, 2003.

[13] PIZZOL, W, A; MAESTRELLI, N, C. Uma proposta de aplicação de mapeamento do fluxo de valor a uma nova família de produtos, SIMEA, 2005.

GIL, A. C. Como Elaborar Projetos de

Pesquisa. 4. Ed. São Paulo. Atlas, 2002. 